\title{
Civilization as a Large-Scale Energy-Information System
}

\author{
V.V. Bushuev \\ Director-General of the Institute of Energy Strategy, Moscow, Russia
}

\begin{abstract}
DEAR READERS!
This issue of the Energy Systems Research journal is opened by a paper which was unexpected for our journal both in the ideas discussed and in the conclusions drawn. The author, V.V. Bushuev, is a well-known power engineer, Doctor Habilitatus in Engineering, Professor, Director-General of the Institute of Energy Strategy, former Deputy Minister of Energy of the Russian Federation, who philosophically addresses the global issues of civilization (who are we, where do we come from, where are we going to?) and interprets these issues in terms of energy development (foresight). The author's target vision relies on the tools for analyzing the cyclical development of civilization as a large-scale energyinformation system on the example of its East Eurasian type for the time horizon until the middle of the 21st century. It is worth placing emphasis on the constructiveness of the 'cyclical' approach to long-term forecasts of energy development used by the author. This approach, as evidenced by the practice of its application, in most cases, provides more reliable results compared to the traditional long-term forecasting methods. This paper will undoubtedly arouse interest among the readers of the journal. Depending on the breadth and depth of this interest, the journal is ready to continue the discussion of the issues raised in the paper.
\end{abstract}

\begin{abstract}
The world is a triadic meta-system: nature - society - man, in which all components are linked by material, energy, and information relationships. These system subjects and their relationships are civilization structures represented by a "community" in our planetary House, i.e., Ecos (from the Greek 'oikos' dwelling in various zones of the earthly oecumene). Civilization is a set of socio-natural factors, the system of life, and cultural-and-mental relations in the ecosystem in its certain evolution stage. Regional and mental features (like apartments in an apartment house) characterize certain historical and geographical types of civilization, among which the Atlantic, EastEurasian, and Islamic ones stand out. All of them are in different stages of their evolution and differ in their material level, the organization of social life, and the target vision of their arrangement.
\end{abstract}

\footnotetext{
${ }^{*}$ Corresponding author.

E-mail: vital@guies.ru
}

http://dx.doi.org/10.38028/esr.2020.02.0007

Received August 18, 2020. Revised September 20, 2020.

Accepted October 10, 2020. Available online October 21, 2020.

This is an open access article under a Creative Commons Attribution-NonCommercial 4.0 International License.

(C) 2020 ESI SB RAS and authors. All rights reserved.
The current stage of the civilization development is characterized by a thorough transformation of all its types under the influence of regular cyclicality and change in the dominant factors of socio-natural relations in the planetary House, given the qualitatively new features of modernity - massive digitalization as a way of integrating the real (material and power energy) and verbal (subtle-energy and information) worlds.

The paper briefly examines historical aspects of the cyclical development of civilization (using the example of its East-Eurasian type) and presents the author's target vision (foresight) of its future for the time horizon until the middle of the 21 st century.

Index Terms - civilization, features, transformation, cyclical development, target vision (foresight), EastEurasian civilization system, energy prospects of East Eurasia.

\section{SPECIFIC FEATURES OF THE PRIMARY CIVILIZATION SYSTEMS OF THE WORLD ARE PRESENTED IN FIGURES 1 AND 2.}

These civilization communities are shaped as the corresponding structures - the Atlantic Alliance, the SCO, and the Arab League, shown in Fig. 2. [1-3].

The fundamental difference between the proposed consideration of various types of civilization in the territory of Eurasia is the focus on natural factors that determine not 


\section{Three types of civilization systems}

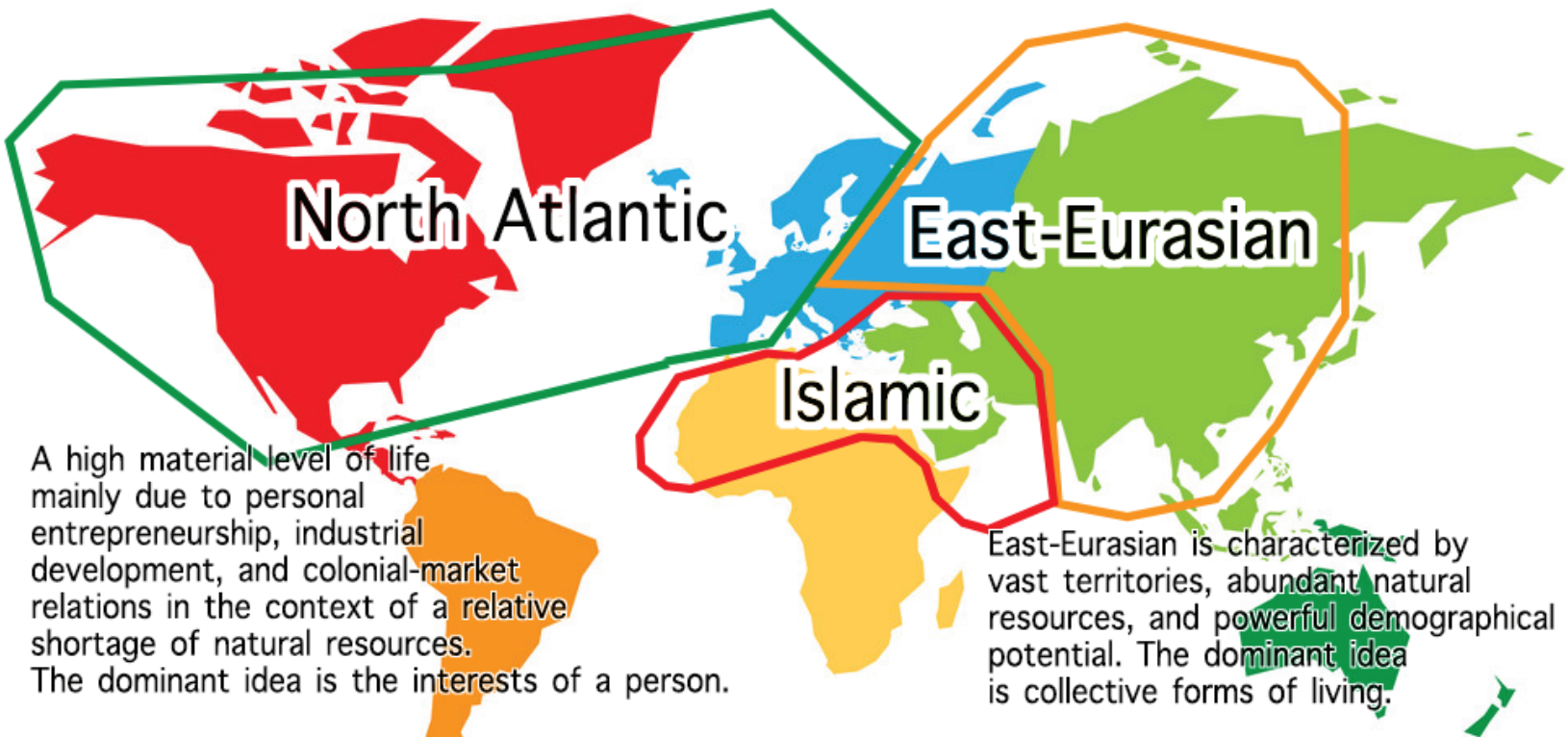

Islamic stands out by high culture in the past and the indigent population at present. The dominant idea is religious commonality, sometimes reaching the fanaticism.

Fig.1. Three types of civilization systems.

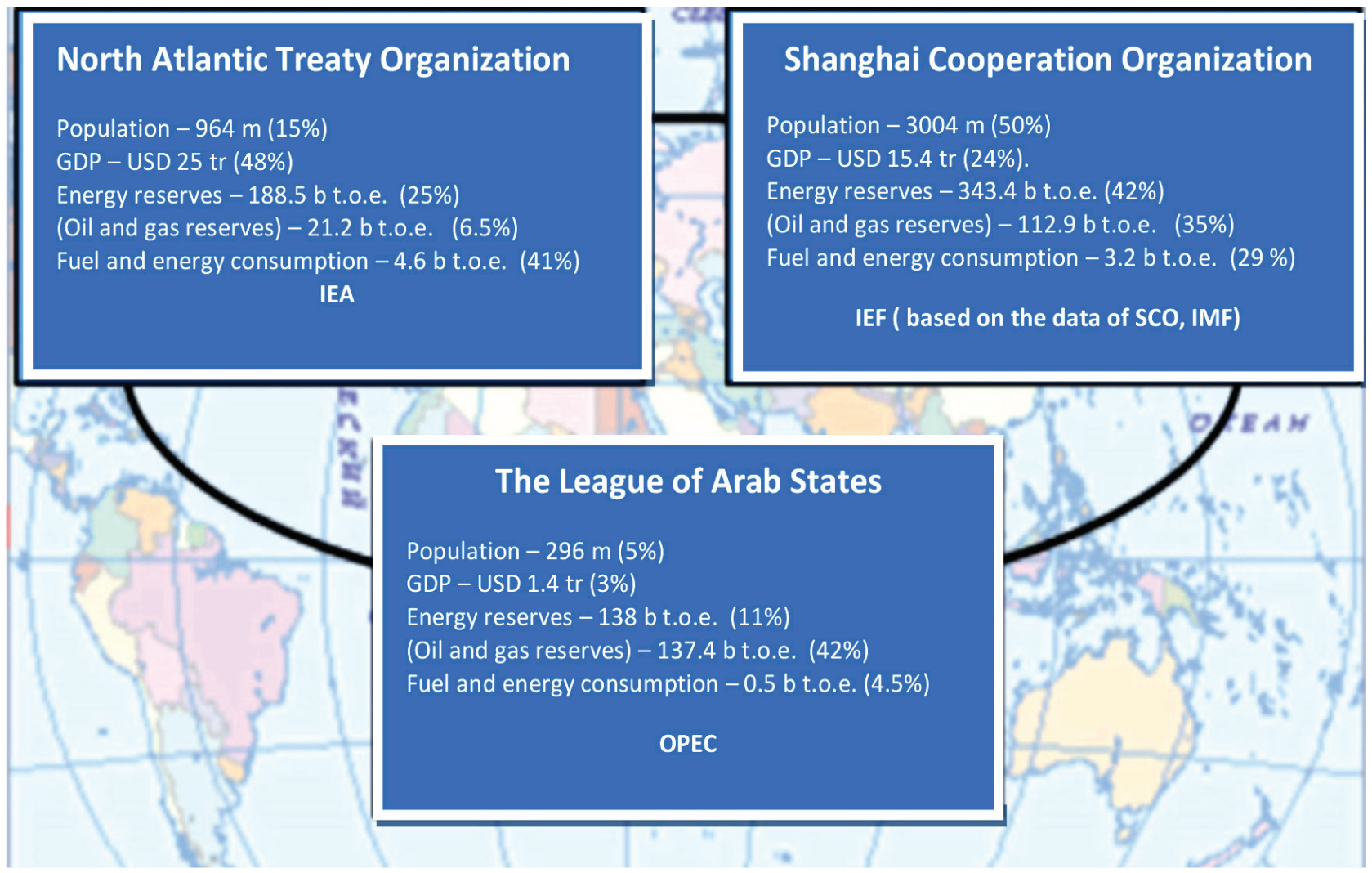

Fig.2. Characteristics of different civilization communities. 


\section{Fractal structure of energy civilization development}

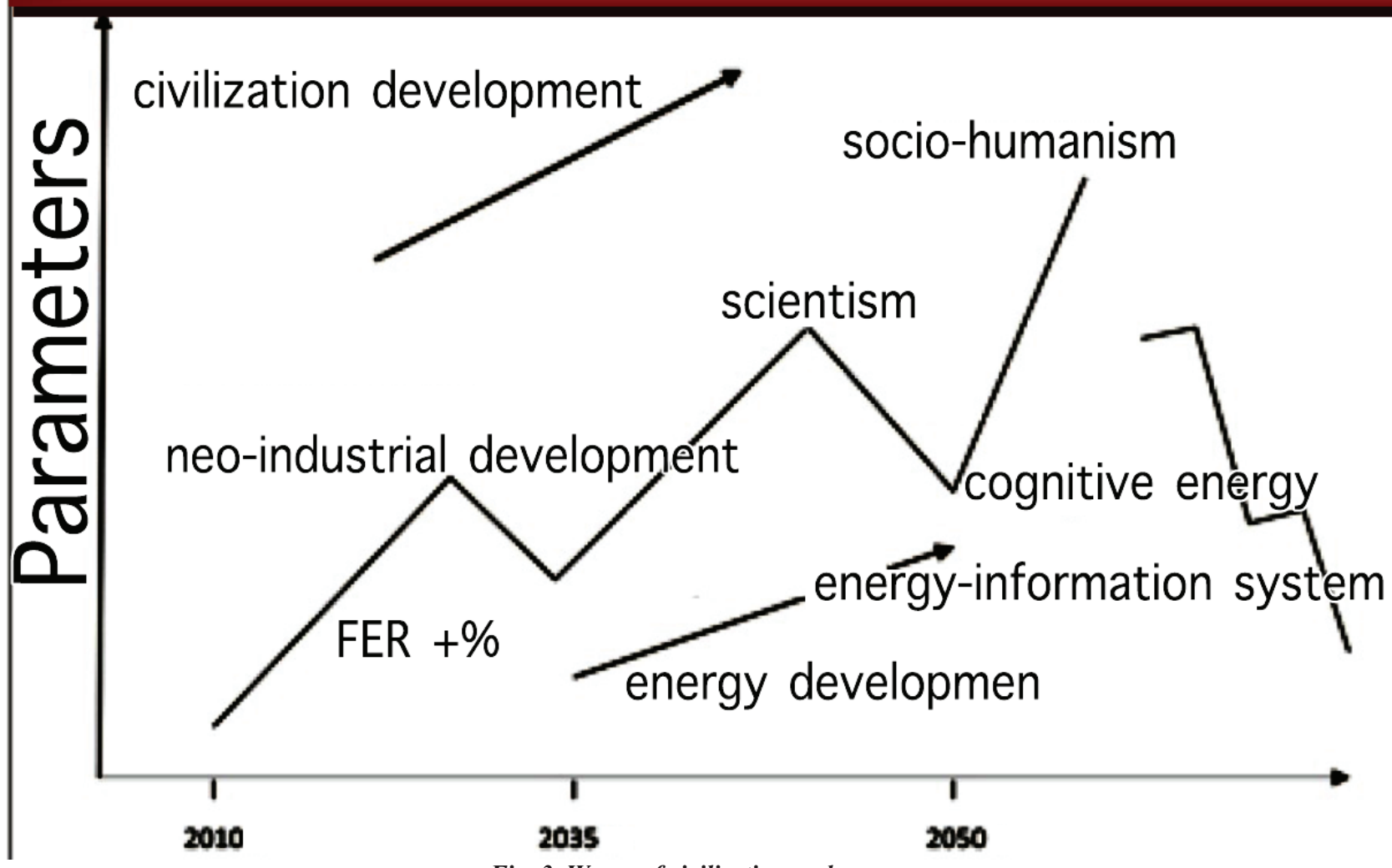

Fig. 3. Waves of civilization and energy.

only geographical and demographic features but also the related mental, social, and technological features of their historical and future development [1].

Vast territories with rich natural resources, high but unevenly distributed demographic capital, a sharply continental and rather harsh climate in most of the EastEurasian oecumene determined the collectivist mentality of the local population and the centralization of management of its social structures. Natural resources of East Eurasia (furs and timber in Siberia, fuel and energy resources of the region, tea, and silk of China) have always been an item of export, which also influences the characteristic features of the enclave (island, oasis) economic development of the territory and the great attention to the organization of internal and external infrastructure. Despite rather significant differences in different countries, the EastEurasian civilization had a fundamental commonality. The collectivist mentality, inherent even in distributed cattle breeding and seasonal production over a large territory, determined the organic perception of communist ideology in the USSR and China, and the "imperial" (autocratic) planned management contributed to the successful progress of the countries in the region. Thus, the Soviet Union had become one of the military-political leaders of the world, and China, in recent years, having retained its historical characteristics, has become a "world factory" that has caught up with the United States in terms of its economic development. The economic development of the Central Asia countries made a colossal breakthrough in the 20th century while maintaining their resource potential, distinctive national culture, and centralized management. India, whose industrial development was not aimed at catching up with Western countries, has become one of the leaders in information innovations. No wonder its programmers are among the most in-demand IT specialists in the world. And it is precisely due to centralization (India has established the world's only Ministry of Renewable Energy), the country is successfully transitioning to new energy sources while maintaining large nuclear power plants and coal-fired thermal power plants. This facilitates a reasonable diversification of the socio-economic life in the region. Further development of the East-Eurasian civilization led to its new structure shaped into the SCO and the EEU [4-5].

The specific features of various civilizations manifest themselves most acutely during the periods of exacerbation of the socio-political, resource-technological, and information-technological situation in the world. Even the current pandemic crisis has shown the versatility and global nature of the world dynamics manifestation, on the one hand, and, on the other hand, it has demonstrated the fact that the countries of the East-Eurasian civilization 
with a dominant collectivist mentality and centralization of public life cope with crises much more effectively than the Atlantic countries with a cult of individualism and decentralization of management. This is indicative of the fact that the market copes well with fluctuations in global dynamics, while active government interference is required to resolve crises.

\section{SPATIO-TEMPORAL (FRACTAL) SEMBLANCE OF CIVILIZATIONAL DEVELOPMENT}

Any development is always cyclical. There are daily, annual, and more extended recurring periods in nature and society. The end of one stage and the beginning of the next are as a rule accompanied by crisis phenomena. Crises are not only a catastrophic manifestation of socionatural, man-induced, and civilization destruction but also the "night before the birth" of new ways of life. Since we all "live in the arms of the Sun" various types of terrestrial processes are subject to cosmic cyclicality [1].

There are three types of crises [6] in civilization development, separating some cycles from others:

- The current parametric crisis is characterized by changes in parameters rather than changes in the basic structure of the dynamic system. Examples of such crises are recurrent natural disasters and manmade accidents (including those at nuclear power plants), intermittent ups and downs in world oil prices, economic recessions, technological transitions to other voltage levels in high-voltage power transmission lines. Such crises are usually separated by 10-12-year periods of cyclical development of the system (Jupiter cycle).

- The structural crises result in changes in the very organization of the system of management and power in society. For example, the transition from the dominant planned management of the economy to the market (economic reforms in China in the 1980s, Gorbachev's perestroika in the USSR). The priorities of technological development change, for example, the beginning of the atomic-space era and oil and gas energy in the USSR in the 1960s. Such turning points have a historical recurrence of 36 (three of 12 years each) years (Saturnian cycle).

- The civilization crises determine radical changes in the dominant type of resource energy potential, a new technological and social way of life in several neighboring countries, and rearrangement of the world structure. Such crises are separated by the socalled "imperial" cycles of 144 years [2] and their subharmonics (two 72-year-long periods, four Jupiter cycles of 36 years, and twelve Saturnian cycles of 12 years).

Such a clear quantitative periodization of world dynamics associated with cosmic cyclicality, of course, does not always correspond to strict time intervals, nevertheless, it reflects the qualitative changes in the development of civilization.

Over the past century, the world has witnessed 4 major oil crises, more than 20 economic crises, 8 virological pandemics with an approximately 12-year periodicity; two global socio-political revolutions (1917 and 1989-1991), separated by the 72-year period of the USSR establishment and disintegration, which had a worldwide resonance.

Despite the significant historical features of various countries of East Eurasia (USSR - Russia, and China) in the 20th and 21st centuries, there are common 36-year cyclical periods of their development. Years from 1917 to 1953 in the USSR, and from 1949 to 1985 in China were the time of the authoritarian leadership (by Stalin and, accordingly, Mao Zedong and his successors) characterized by the formation of socialist ideas and temporary repressive actions. The period from 1953 to 1989 (from Khrushchev to Gorbachev) in the USSR saw the establishment of the atomic and space industry; the development of virgin lands; the construction of the BAM, the hydroelectric power plants of the Angara-Yenisei cascade, and the West Siberian oil and gas industry. China, pursuing Deng Xiaoping's ideas, went through a course of economic reforms, and in 36 years (from 1985 to 2021) has become the second economic power in the world. Post-Soviet Russia (from 1989 to 2025) has gone through a series of difficult transformations in the transition to a market economy, and the restoration of the national defense and economic level.

All the countries of East Eurasia are experiencing, albeit with a shift by one cycle, the general dynamics of civilization transformations, relying on their resource capabilities, including demographic ones, and on an authoritarian organization and their mentality.

Following this logic of cyclical development, by the beginning of the 2060s, we should expect the end of the 144-year "imperial" cycle in Russia (1917-2061), which will correspond to the 36-year "night before the birth" (2025-2061) of the new arrangement of the country. This time will correspond to the 36-year stage of economic stability in China (2021 -2057) with subsequent stagnation and the stage of economic prosperity in India (and other SCO countries).

In the Atlantic civilization, this period will be characterized by the collapse of the military-political NATO bloc, the loss of the monopoly leadership by the United States, and a change in the dominant idea of economic development with the rejection of material consumerism in favor of the "green world".

After that, there can be a transition from the state model to the network model of public life organization, i.e., a change in the civilization development paradigm itself. This is already beginning to be seen in the development strategies discussed both in the Atlantic world and in the East-Eurasian civilization. 
The coming period will be the time of radical transformations not only in the material and energy sphere of life but also in the sphere of information and intellectual development. The key factor of such transformations will be the common energy of nature, society, and human.

The transition from one structure of civilization to another (from industrial development to socio-humanism) (Fig. 3) is inevitably accompanied by the transformation of energy as a potential for development, and a system of life. The forthcoming transformation is related not only to a change in the dominant energy carriers, i.e., the transition from coal and oil to gas and electricity but also to the integration of power, bio- and "subtle" energy, which ensures the unity of the material and mental worlds.

The spheres of cognition and life in the East have always relied on the energy-based similarity of Man and the Universe [7]. The very expression "qi" (energy) was the root basis for such concepts as a cycle - an energy wheel (the principle of the cyclicality of all world processes), a figure (another form of energy), information (another form of action) and even the concept of civilization - a system of energy ownership. No wonder it is in the East where qigong is widespread as a method of treating people by controlling their energy. The very image of Man and the Earth is a multidimensional energy representation of both the physical body and the seven surrounding energy spheres of the etheric, astral, mental, and other bodies. Through these spheres, man and the Earth carry out energy communication with the surrounding world, when cosmic energy interacts with internal biophysical and cognitive energy through the corresponding chakras, and the results of the intellectual life of the system ascend into the noosphere, replenishing the overall potential of the Worldsystem [7].

Even today, cosmic energy is involved in building the energy potential of the subsoil, water, and atmosphere. Therefore, all energy resources of the planet, including hydrocarbons, gas hydrates, and heat of the deep layers of the Earth (and not only solar and wind renewable energy sources), are renewable energy potential. The energy of the Sun participates in the accumulation of the creative spiritual potential of people, which is an important component of the human potential of civilization. Solar activity creates conditions for the formation and manifestation of the passionarity of the human community leaders, who are most responsible for the accumulation of the potential and the active life of society. Moreover, it is the energy interaction of the anthroposphere and technosphere with the environment that determines the harmonious codevelopment of nature and society.

Energology, as a general science about various types of energy, their commonality, and transformability, about the general energy laws of the universe, allows us to better understand the energy unity of the world and use this concept to establish the future energy-information system of civilization.

\section{THE MAIN DIRECTIONS OF ENERGY FORESIGHT FOR THE FORTHCOMING 36-YEAR PERIOD OF THE CIVILIZATION CYCLE.}

The current crisis, whose distinctive feature is simultaneous manifestation of coronavirus pandemic, economic crisis and plunge in prices in the world energy markets, which are accompanied by the collapse of the main ideological and socio-political foundations of society and their changes, is only an overture to the global break in the world order to be expected by the end of the forthcoming 36-year stage (up to the beginning of the 2060s), according to the general cyclical dynamics of the World-system.

For some obvious reasons, such as the desire for selfisolation of states in the context of anti-quarantine measures, the rapid development of the "online" principles in many areas of activity, the partial rejection of hydrocarbon energy due to fears of global warming, the development of new waste-free nature-like technologies, and the active advancement of the Internet of Things and the Internet of Knowledge, we can claim that the upcoming transformation of life will affect many basic foundations of civilization and will require qualitative changes in the technological, informational and organizational ways of life. All these changes are in one way or another connected with the energy of the future - its transformation from a system of energy supply to society into a system of its vital activity. After all, energy is every action, work, including life itself, while the energy potential (natural and man-made) is only an opportunity for life. The 20th century was a period of active industrial advancement of the entire civilization system, including the East-Eurasian one, based on the massive electrification of production and everyday life. With the beginning of the millennium, the world entered a qualitatively new period of its development characterized by the integration of the physical (energy) and information patterns of life. The upcoming 36-year Saturnian cycle (from 2025 to 2061) of civilization development will be the heyday of this hybrid world.

\section{MAJOR CHANGES IN THE STRUCTURE OF THE WORLD ENERGY AND ITS EAST- EURASIAN WING.}

The current ideas about the forthcoming energy transition that are widespread among representatives of the Atlantic civilization system and imposed on the whole world require critical rethinking in terms of specific features of the development of various civilization systems. The general recipes for the three Ds (decentralization, decarbonization, and digitalization) of the world energy can hardly be applied by all regions of the Earth's oecumene due to their historical and geographical features. Centralization in the development of the East-Eurasian civilization, as shown above, is caused by its natural (resources, including demographic ones) characteristics, extended territory, and collectivist mentality. Therefore, East Eurasia will still have both a high degree of life urbanization and a significant role of raw materials in 
the economy and centralized energy sector. This does not mean energy stagnation. Undoubtedly, the refining sectors will also actively expand here, including oil, gas, and coal chemistry. However, the need for more comprehensive development of the still sparsely populated territories of the Russian Far East and Western China will require corresponding large-scale energy development, which cannot be pursued only through decentralized systems $[8,9]$. In addition to the development of energy-intensive mining resources, including not only the exploitation of hydrocarbon reserves but also the extraction of rare earth materials, the centralization of energy supply will be required to create territorial-production clusters, which have been and will be the main type of organization for the economic development of extended and sparsely populated areas. It stands to reason that small-scale energy will find a wide application here in organizing the life of individual regions, but it will not become an alternative to large-scale energy - it will only become its supplement. To select certain development options, an empirical relationship is quite suitable: with a load concentration of more than $40 \mathrm{~kW}$ per $\mathrm{km}^{2}$, two-thirds of the demand will be met by centralized energy sources, and one-third - by distributed energy, including local and renewable energy sources. At a load density of less than $10 \mathrm{~kW}$ per $\mathrm{km}^{2}$, the relationship is inverse.

For East Eurasia, the main energy issue is the infrastructural development of the territory $[10,11]$. It is not about expensive energy transport communications, pipeline or power grid, rail or road, connecting individual districts of industrial and energy production and consumption, which are located far from one another. It is impossible and impractical to provide the same density of infrastructure in the extended territory of East Eurasia as in Europe. Here it is quite appropriate to employ another infrastructural principle, such as network structures or energy rings that connect separate oases (as in the old days) or individual modern and future territorial production complexes (TPC).

The Asian energy ring proposed in the works by researchers from the Melentiev Energy Systems Institute of Siberian Branch of the Russian Academy of Sciences [12], in our view is a "busbar system" that represents various transport and energy communications, to which both large generating units (nuclear, thermal, hydraulic and tidal power plants) and load centers (TPC) are connected. Elements of these rings can be various communications (oil and gas, coal and electric, hydrogen and methanehydrate), in the form of mutually complementary now and hybrid system-wide energy transmissions in the future. According to the same principle, hydropower and watertransport links of East Eurasia can and should develop in the future. At the same time, using the example of the Casa-1000 project [1], we can talk about the transfer of water resources from Siberia to Central Asia for irrigation, and the use of the Pamir hydroelectric power plants for generating electricity and its subsequent transit to Pakistan and India. And hydro-energy and transport communications in the Arctic and the South China Sea will make it possible to effectively use the water resources of Eurasia for infrastructural, irrigation, and climatic support of the sustainable development of civilization.

For the development of infrastructure systems in the region, of great importance will be storage systems converters that make it possible not only to store energy for a long time but also to transform various energy types into each other, creating a common interregional energy interconnection for the integration of resources and centers of various energy consumers. In particular, integrated power complexes in the region of the Sea of Okhotsk, which consist of tidal hydroelectric power plants and local use of their energy for electrolysis of seawater, production, and liquefaction of hydrogen, with its subsequent export to other regions of Eurasia, can play the role of such storage devices.

In the future, energy rings can also be transformed into energy-information communications, where physical flows can be partially replaced by virtual (financial and information) ones, contributing to the integration of individual regions of the East-Eurasian civilization.

The principle of decarbonization in East Eurasia in connection with the sufficiently large gas resources available here (including those produced during the gasification of coal deposits, gas hydrate and biogas reserves from the processing of wood waste and agricultural waste, and the disposal of organic waste) should lead not to the widespread transition to renewable energy sources, but to the replacement of the "green energy" paradigm with "blue energy" one [13]. The contribution to solving environmental problems will not be less, but it will provide more efficient use of existing resources, those, which are not available in Europe and which make up the invaluable wealth of East Eurasia.

\section{THE MAIN DIRECTIONS OF DEVELOPMENT OF ENERGY- INFORMATION SYSTEMS}

The main directions of development of energyinformation systems in the era of transition to a new structure of civilization development suggest not just the expanded use of digitalization for processing large amounts of data (Data-systems) but the organic adoption of computer capabilities into our life. The world of physical realities is changing to the world of the Internet of Things and the Internet of Knowledge. Even here, however, it is necessary to take into account the specific features of the East-Eurasian civilization. The material interests of people, the desire for an excess of things and goods have never dominated it. In Russia, in China, and in India, people's interest in the virtual world, the world of spirituality and illusions, the world of noospheric knowledge, the cosmic unity of Man and the Universe have always predominated and survived. It is the countries of this region, primarily Japan, that have recently started to follow the principle 
of material poverty and immaterial happiness. It is not without reason that India is one of the leading countries in the world in self-reported happiness, despite the low level of material wellbeing. Therefore, by the middle of this century, one should expect the energy-information world advancing towards socio- and cosmo-humanism focused not on the dominant idea of material development, but on the completeness of the human view of life. The catch-up path of material development, which is followed by China and which Russia is trying to follow, is a deadend of evolution for the countries of Eurasia. The energyinformation virtual world, which has already become the world of the younger generation, is the world of new energy-cosmism. The end of the "imperial" development cycle of the East -Eurasian civilization is not the end of its centralized development, but a turn of the vector towards the Cosmos.

The Cosmos is viewed not as a place for the extraction of new resources, new sources of energy, and interplanetary travel, but as our past, where we all came from, and our future. K.E. Tsiolkovsky wrote at the dawn of cosmonautics: "in the future, humanity will turn into radiant energy and set off to explore new outer spaces" [14]. Russia is not a bridge between east and west, north and south; it is a bridge between the Earth and the Space. Cosmic energy will be closely connected with the use of bio- and cognitive energy of man, who is going through the transition from Homo sapiens (intelligent man) to Homo faber (man the maker). The noosphere is not a mythical notion of Russian cosmists, but the virtual energy-information world from where we draw natural forces and inspiration, where we bring our creative concepts and ideas for future generations. Digitalization and informatization as new forms of energy activity will allow us to integrate (albeit in a virtual form) the Earth oecumene and the noospheric Cosmos.

The East-Eurasian civilization is an energy-cosmic civilization of the future, which will become the leader of world development by the middle of the $21^{\text {st }}$ century.

\section{REFERENCES}

[1] Eurasian Energy Civilization. Regarding «Future Energy». Moscow. «Energy center», 2017.192p.

[2] Greater Eurasia is not a choice between Europe and Asia, but a common space. Valdai Club. [online]. Available at: http: //valdaiclub.cpm (accessed 05.06.2018).

[3] Tselishchev I.S. East Asia: A new wave of growth and structural transformation. M .: IMEMO RAN, 2012.256 p.

[4] Nazarbayev N.A. Strategy for a radical renewal of global society and partnership of civilization. Astana. ARCO LLP, 2009.224 p.

[5] Mansurov T. Annals of Eurasian Integration, Economic strategies, 2019, no.6 (164), pp. 31-45.

[6] Bushuev V.V. Quo Vadis?, Energy Policy, 2020, no.6. pp. 36-47.
[7] Bushuev V.V. Introduction to Energology. M.: "Energy" Publ., 2019. 252 p.

[8] Mastepanov A.M. Big cycles and "black swans", Energy Policy, 2020. no.6, pp. 4-20.

[9] Simonov K.V. From "resource nationalization" to "molecules of freedom" and the "green revolution", Energy policy, 2020, no.8. pp. 28-37.

[10] Yakunin V.I. Integral project of solidarity development on the Euro-Asian continent (scientific and practical concept), Vestnik RAN, 2014, v. 84, no.8 pp. 67-75.

[11] Trans-Eurasian belt "Razvitie" (collected papers). M.:"Pronsis" Publ., 2012. 264 p.

[12] Belyaev L.S., Voropai N.I., Podkovalnikov S.V., Shutov G.V. Problems concerning the formation. Electricity. 1998. no.2, pp. 15-21.

[13] Gromov A.I. Is the "gas" transformation possible in a post-covid-19 future?, Energy Policy, 2020, no.7. pp. 58-70.

[14] Chizhevsky A.D. On the shore of the Universe memories about Konstantin Tsiolkovsky. M.: "Mysl" Publ. 1995.735 p.

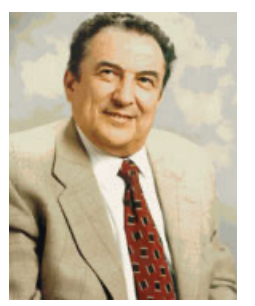

Bushuev Vitaly Vasilievich is Doctor of Technical Sciences, PDr. Habil.in Eng., Professor Bushuev V.V.

Director-General of the Institute of Energy Strategy, Full member of the Academy of Engineering and the Russian Academy of Natural Sciences, laureate of the RF Government Prize in the field of science and technology, honorary power engineer. 